\title{
Physical and Mental Well-Being of Women in Neurodiverse Relationships : A Comparative Study
}

Pnina Arad ( $\nabla$ pninacoaching@gmail.com )

Professional School of Psychology https://orcid.org/0000-0002-7784-1209

\section{Zipora Shechtman}

University of Haifa

\section{Tony Attwood}

Griffith University

\section{Research}

Keywords: autism spectrum disorder (ASD), high-functioning autism (HFA), neurodiverse relationships (NR), well-being, abuse, women, health, depression, distress, emotional deprivation

Posted Date: October 21st, 2021

DOI: https://doi.org/10.21203/rs.3.rs-955119/v1

License: @ (i) This work is licensed under a Creative Commons Attribution 4.0 International License. Read Full License 


\section{Abstract}

\section{Background}

There are very few studies which look into the ways in which autism spectrum disorder (ASD) impacts romantic relationships. The existent sources of information indicate that women in neurodiverse relationships experience extreme emotional deprivation and suffer from severe harm to their physical and mental well-being. The aim of the present study was to conduct empirical research into the question of whether a relationship between a neurologically typical woman and a man with high-functioning autism is significantly different from a neurologically typical relationship and what effects relating with someone with autism may have on the physical and mental state as well as sense of well-being of neurologically typical women.

\section{Methods}

The research population included 648 women in three groups: 228 women whose partners were formally diagnosed on the autism spectrum; 203 women who suspected their partners to be on the autism spectrum; 217 women in the control group, with neurotypical partners, who were neither diagnosed nor was there any suspicion of autism. Data collection was performed through online self-report questionnaires. Data analysis was conducted with SPSS ver. 24.

\section{Results}

Findings showed significantly higher rates of psychological and physical abuse reported by women in neurodiverse relationships (study groups), in comparison to women in neurologically typical relationships (control group). Women in the study groups reported significantly lower perceived physical health, more somatic symptoms and higher somatic symptom severity, as well as significantly higher levels of depression, higher depressive symptom severity and significantly lower levels of subjective well-being than women in the control group. There was no significant difference between women whose partners have been formally diagnosed with autism and for women who suspect their partners to be on the autism spectrum.

\section{Limitations}

The main limitations of the study were reliance on self-report instruments, the use of convenience sampling and the impossibility of pointing towards causation.

\section{Conclusions}

The present study with its preliminary findings enriches the current literature, which is lacking. These findings help to better understand the condition of women in neurodiverse relationship and support the need to provide better therapy and health services for women and couples in neurodiverse relationships.

\section{Background}


Most people do not realize how common the phenomenon of neorodiverse relationships is worldwide. There does not yet exist a broad clinical and public awareness of adults with high-functioning autism, nor enough information about the well-being of women in such relationships. This topic has received very little attention in the literature and in research. The authors of this paper intended to fill this gap and conducted an empirical study exploring the experiences and health condition of women in neurodiverse relationships. Our study contributes to the sparse knowledge base and attains an informed statistically significant understanding of the physical and mental well-being of women in neurodiverse relationships. The findings presented are distressing and may stimulate an international multidisciplinary effort to change the recognition and treatment of women in neurodiverse relationships.

High-functioning autism (HFA), formerly known as Asperger's Syndrome, is a neuro-biological developmental disorder first described by Hans Asperger in 1944. It was given scientific recognition much later, in 1981, as a result of an article published by Lorna Wing (Wing 1981; Baron-Cohen, Wheelwright, Robinson \& Woodbury-Smith, 2005). Asperger's Syndrome was first incorporated into the DSM-IV in 1994, under a category referred to as pervasive developmental disorders (PDD), which included four different syndromes (American Psychiatric Association, 1994). The syndrome that had the most significant effect on a shift in awareness was Asperger's, as it included people with normal cognitive and communication skills who exhibited some form of irregularity in their social skills (Attwood, 2006).

In May 2013, DSM-5 was published, introducing a dramatic change in the definition of autism. The term PDD was exchanged with the term ASD (autism spectrum disorder), thus replacing the four previous and separate terms that had been used in DSM-IV. The transition from multiple diagnostic categories to one single concept reflected a scientific consensus that the diagnoses that were previously divided into four subcategories were in effect referring to one mental state with varying levels of severity and symptomatic signs in two main areas: deficits in social communication and restricted, repetitive patterns of behavior (American Psychiatric Association, 2013).

From a clinical standpoint, it has been found that adults with ASD have higher rates of psychiatric comorbid disorders, such as various personality disorders, obsessive-compulsive disorders, attention deficit disorders, learning disabilities, eating disorders and mood disorders, that may accompany ASD or develop subsequently as a side effect of ASD (Lai \& Baron-Cohen, 2015 ; Lehnhardt et al, 2013). While there is a consensus that the disorder has a genetic component, the complexity and lack of distinct biological signs hinder the diagnositic process and make it especially challenging to detect with certainty (Attwood, 2006).

The most recent formal estimated rate of diagnosis with ASD is about 1 in every 54 eight -year-old children in 11 communities across the United States, or around $2 \%$ of the general population, according to a report based on data from CDC's Autism and Developmental Disabilities Monitoring (ADDM) Network (CDC March 2020). ASD is about 4 times more common among boys than among girls (Baio et al, 2018).

Since Asperger's was first introduced into the DSM in the 90's, there has been a steady rise in the rate of patients diagnosed with autism, an association that can be mainly attributed to updates made in the 
diagnostic criteria and a rise in public awareness concerning the disorder. We now know that the incidence among children and adults on the autism spectrum is identical (Center for Disease Control and Prevention, 2016). "The lost generation" is a term used in reference to adults who weren't diagnosed in their youth due to lack of criteria, prior to the release of updates in DSM-IV concerning Asperger's (Lai \& Baron-Cohen, 2015).

Adults with HFA do in fact manage to participate in and be involved in normal social institutions. Many of them learned how to live with their social limitations due to the support they received from parents and the strategies and coping mechanisms they developed throughout their lives. However, the vast majority of adults with HFA who are undiagnosed manage a complex variety of significant and unexplained challenges which affect their social interaction as well as their intimate relationships (Baron-Cohen etal, 2005 ; Myhill \&Jekel, 2008; Attwood 2006).

While the communities awareness of autism continues to show signs of growth little empirical research has been done on the way in which autism manifests itself within the context of romantic relationships and how it affects the partner of the one diagnosed with the disorder. The current literature on the subject is mainly based on personal accounts of women involved in these types of relationships (Bostock-Ling, Cumming \& Bundy, 2012).

Neurologically typical (NT) is a neologism widely used in the autistic community as a label for people who are not on the autism spectrum. The term neurodiverse relationships (NR) is often used to describe intimate partnerships between one NT partner and one partner who is on the autism spectrum. Accordingly, intimate partnerships between two NT partners can be termed neurologically typical relationships (NTR).

According to the existent body of knowledge, women who are in NR report a pattern of ongoing emotional and sexual deprivation, as well as physical and mental symptoms that are reminiscent of symptoms of trauma and post trauma (Lewis, 2017). They describe a relationship categorized by domestic, physical and mental abuse (Rench, 2014), extreme challenges in communication and high levels of conflict (Aston, 2001, 2003 ; Bolling, 2015 ; Bostock-Ling, 2017 ; Bostock-Ling, Cumming \& Bundy, 2012 ; Grigg, 2012 ; Millar-Powell, 2015 ; Myhill \& Jekel, 2008).

Personal accounts of women in NR point towards significant negative effects of the relationship on their physical and mental health. What is common for most women in NR is a sense of: loneliness, confusion, frustration, desperation, mood swings, low self-esteem, problems with intimacy and the feeling that their sanity is being questioned. Their recurring complaints focus on the absence of emotional support and empathic understanding from their partner with ASD (Aston, 2001, 2003 ; Bolling, 2015 ; Bostock-Ling, 2017 ; Bostock-Ling, Cumming \& Bundy, 2012 ; Grigg, 2012 ; Millar-Powell, 2015 ; Myhill \& Jekel, 2008 ; Rench, 2014).

The literature suggests that a lack of competence of professionals in psychology and psychiatry in identifying symptoms and diagnosing ASD in adults, not only leaves these women without an effective 
response to their complaints, but in many cases, the inability to validate women's experiences and alleviate their distress worsens their condition (Aston, 2001, 2003 ; Bolling, 2015 ; Bostock-Ling, Cumming \& Bundy, 2012 ; Grigg, 2012 ; Millar-Powell, 2015 ; Myhill \& Jekel, 2008 ; Rench, 2014).

A small number of empirical studies investigated how ASD influenced intimate relationships. These studies focused on marital satisfaction and exhibited contradicting results. Bolling (2015) found a statistically significant higher rate of marital dissatisfaction in NR than in NTR. The NT partner was less satisfied than the partner with ASD and women reported to experience more dissatisfaction with regards to sexual intimacy than men. Millar-Powell (2015) also found significantly lower levels of relationship satisfaction in NT women than in their ASD partners. Two previous studies did not find differences in the level of marital satisfaction when one of the partners most likely had ASD, without being formally diagnosed (Lau and Peterson, 2011 ; Pollmann, Finkenauer and Begeer, 2010).

Renty and Roeyers (2007) found that increased levels of support on behalf of the partner with ASD led to higher levels of satisfaction in the marriage and that the amount of autistic traits had a negative effect on the couples' ability to adapt to married life. Vaughn (2010) found that the amount of autistic traits influenced marital expectations. People with less autistic traits had higher expectations from their partner, while people with greater characteristics of autism had lower expectations from their partner.

Bostock-Ling (2017) investigated the life satisfaction of women in NR. The research group consisted of 500 female participants, 321 women whose partners were formally diagnosed and 177 women, who suspected their partners to have ASD. The control group included 53 women. The results showed that women in the research group experienced a statistically significant lower level of subjective well-being than women in the control group and than a normative sample of Australian women in all the compared domains. No significant statistical difference was found between women whose partners had a formal diagnosis and women who suspected their partner to be on the autism spectrum.

Bostock-Ling, Cumming and Bundy (2012) conducted a systematic literature review to study the influences of autistic traits on the mental well-being of NT women in NR. The decision was made to accept an informal diagnosis of autism. The articles that were chosen to be relevant had undergone academic peer review. Ultimately, out of 1736 articles derived from the initial archive search, there were only ten articles that met the inclusion criteria determined in advance, and six of these were case studies. None of these studies included intervention and they received a low overall grade based on the levels of proof and guidelines recommended by the Australian National Health and Medical Research Council. In summary, none of these studies provided reliable proof about the manner in which autistic traits affect the neurotypical (NT) partner in an intimate relationship. The systematic review indicated a lack of proofbased literature, and highlighted a lack of high-quality studies on which one may base conclusions about the mental well-being of NT women in neurodiverse relationships.

\section{The Present Study}


In order to increase knowledge about this important topic and change the existing situation, we conducted a quantitative study based on empirical data. Our aim was to find out what effects relating with someone with autism may have on the physical and mental well-being of NT women.

We hypothesized:

1. Women in NR and women who suspect their partner to be on the autism spectrum will report being subjected to physical and psychological abuse at a higher rate than women in NTR.

2. Women in NR and women who suspect their partner to be on the autism spectrum will report lower physical and mental health than women in NTR.

3. Women in NR and women who suspect their partner to be on the autism spectrum will report experiencing symptoms of depression more noticeably than women in NTR.

4. The personal sense of well-being of women in NR and women who suspect their partner to be on the autism spectrum will be reported as worse than the personal sense of well-being reported by women in NTR.

\section{Method}

\section{Participants and Procedures}

The research population included 648 women in three groups: 228 women $(35.2 \%)$ whose partners were formally diagnosed on the autism spectrum; 203 women (31.3\%) who suspected their partners to be on the autism spectrm; 217 women (33.5\%) in the control group, with neurotypical partners, who were neither diagnosed nor was there any suspicion of autism. The three main diagnoses reported among women whose partners have been formally diagnosed were: Asperger's (70.6\%), HFA (14\%) and ASD (12.3\%). We chose to categorize all as ASD diagnoses to allign with the current DSM.

All women participating in the research were in the past or currently in a relationship with a man, for a period of at least one year and were above the age of 18. The average age of the participants was 42 $(S D=10.76) .86 \%$ of the participants were in long-term relationships, with an average length of 13 years $(S D=10.21) .82 \%$ of the participants were living together, $60 \%$ of the participants had children, $70 \%$ of the participants were employed. The participants had an average of 15 years of education $(S D=4.35)$. Most respondents were from the United States. Others were from European and English speaking countries (see table 1).

The study was a correlational research of an exploratory nature, using a type of non-probability sampling known as convenience sampling. An internet site was constructed which provided detailed information about the study in English, with links to a research consent form and questionnaires. Participation in the study was anonymous, voluntary, and the identifying details of the participants were kept secret by means of strict technological security measures. All procedures performed were in accordance with the ethical 
standards of the institutional research committee and with the 1964 Helsinki declaration and its later amendments.

Data collection was performed between August-December 2017. Information regarding the study was publicized over the world-wide web through websites and forums for people with autism and their families and through support groups for women in NR. The information was also distributed through professionals in the field of autism and counselors treating neurodiverse couples.

Participants in the control group were recruited through Amazon's MTurk service, a popular source of collecting research data for studies in psychology. MTurk is a large employee internet market which enables researchers to quickly collect high quality data with low cost. It was supported by evidence that data gathered through this service is not less reliable than data collected by means of other traditional data collection methods (Buhrmester, Kwang \& Gosling, 2011).

\section{Measures}

Data collection was performed through online self-report questionnaires. All rating scales were found to be highly reliable and valid in previous studies and were used in their language of origin (English).

\section{Abusive Behavior Inventory (ABI)}

This is a self-report questionnaire (Shepard \& Campbell, 1992), comprised of 30 items that describe a wide range of harmful behavior and reflect patterns of physical abuse (10 items), (e.g. inflicting violence, forcing sexual activity etc.) and psychological abuse (20 items), (e.g. humiliation, isolation, threats, financial abuse etc.). The responses range on a scale of 1-5 where 1 indicates a negative "never" response and 5 indicates a high frequency of occurrence. A total score was calculated for each scale, using the items' averages, so that a higher score indicated a higher frequency of abusive behavior.

The validation study of Shepard \& Campbell (1992) included 4 groups and the reliability of the ABI was assessed by examining the alpha coefficient. The alpha coefficients for the four groups ranged from $0.70-$ 0.92. The results of the study included three types of validity: criterion related, construct and factorial. The data pointed towards a strong correlation between physically violent threats, aggression towards objects and instances of assault towards women. After the recommendations of the authors were implemented, the alpha coefficient for the psychological abuse evaluation ranged between $0.76-0.91$. The internal consistencies found in the current study were: for physical abuse: $a=.86$. For psychological abuse: $a-93$.

\section{Perceived Health Questionnaire}

This self-report questionnaire (Hobfoll et al, 2012) is comprised of four questions:

- In general, would you say your health is excellent, good, fair, or poor?

- To what extent do you have any particular health problem?

- Thinking about the past 2 months, how much of time has your health kept you from doing the kinds of things other people your age do? 
- To what extent do you feel healthy enough to carry out things you would like to do?

Answers are given by numbers ranging from 1-5 where 1 indicates a low level of occurrence and 5 indicates a high level of occurrence. The questionnaire is registered as valid and reliable (Cronbach's alpha coefficient: 0.78). The direction of the items was inversed in the present study in such a way that a higher score signified better perceived health. Good internal consistency was found: $a=.88$.

\section{PHQ15, 15 - item Patient Health Questionnaire}

The questionnaire (Jasper et al, 2012) has been derived by Kroenke et al (1998) from a larger mental health survey. It is comprised of 15 items, 13 of which refer to physical symptoms such as: stomach pain, back pain, headaches, dizziness, and the last two items $(14,15)$ : difficulty sleeping and lethargy or low energy level, which are signs of depression. The questionnaire examines the severity of the symptoms over the course of a four-week period directly preceding the time the questionnaire is filled out.

Answers are given by a number ranging on a scale made of three parameters: Not bothered at all, Bothered a little, Bothered a lot. The answers are grouped into three separate scores : 5, 10, 15 where a score of 0-4 indicates that the severity of the symptoms is low, a score of 5-9 indicates the severity of the symptoms is medium and above 10 indicates the severity of the symptoms is high. The questionnaire has a strong internal reliability factor (Cronbach's alpha: 0.80 ) and a repeat testing reliability score of 0.60 two weeks later (Van Ravesteijn et al, 2009).

In the present study, good internal consistency was found for a measure comprised of 15 items: $a=.85$, as well as for a measure comprised of 13 items: $a=.82$. A high correlation was found between the two items representing symptoms of depression: $r=.45(p<.001)$. Hence, three measures were defined according to the sums of the items: an overall measure, a measure of physical symptoms and a measure of depressive symptoms. A higher score representing a higher rate of severity symptoms.

\section{Beck Depression Inventory}

Beck's Depression Inventory (Beck et al, 1996) is a self-report questionnaire comprised of 21 questions measuring physical and cognitive affective symptoms. The questionnaire serves as a reliable measurement of signs of existing depression and the severity of symptoms of depression. Every question has four possible answers ranging on a scale from 0-3, and escalate in their level of severity for example: 0-I don't feel sad, 1-I feel sad, 2-I am sad all the time and I can't snap out of it, 3-I am so sad and unhappy that I can't stand it.

Scores range between 0-63, where a high score indicates signs of depression that are extremely severe. The clinical categories are: minimal range (0-13), low range (14-19), medium range (20-28), severe range (29-63). Good internal consistency was found in the present study: $a=.93$.

\section{Subjective Well-Being (SWB) Short Scale}

This self-report questionnaire (Roysamb et al, 2002) has been developed by Moum et al (1990). The questionnaire is registered as valid and reliable with solid psychometric qualities (Cornbach's alpha: 0.71), 
comprised of 4 questions:

- When you think about your life at present, would you say you are mostly satisfied with your life or mostly dissatisfied?

Six response categories are used for this question ranging from $1=$ extremely satisfied to $6=$ very dissatisfied.

- Are you usually happy or dejected?

The five response categories ranged from $1=$ dejected to $5=$ happy.

- Do you mostly feel strong and fit or tired and worn out?

The four response categories ranged from 1 =strong and fit, to $4=$ tired and worn out.

- Over the last month, have you suffered from nervousness (felt irritable, anxious, tense, or restless)?

The four response categories ranged from $1=$ almost all the time, to $4=$ never.

The index comprised both a cognitive aspect (i.e. life satisfaction), as well as a positive affect (i.e. happy, strong) and negative affect (i.e. tired, nervous). A total score was calculated for the scale using the average scores of each of the four questions. Higher scores reflected higher rates of SWB. Due to diversity in the response category (ranging from 4-6), all items were transferred to scales ranging from $0-10$, in order to form a common metric scale.

Good internal consistency was found in the present study: $a=.78$. After conversion, the measure was defined according to the items' averages, ranging from $0-10$, in such a way that higher scores represented higher levels of SWB.

\section{Informative Questionnaire for Women}

This is a basic demographic questionnaire created by the authors. It includes informative questions about the female participants (such as: age, country of birth, years of education, occupational status), questions that refer to their relationship status (such as: single, married, length of time, children) and questions that relate to the formal diagnosis or lack of formal diagnosis of the partner who has ASD.

\section{Statistical Analyses}

Data analysis was conducted with SPSS ver. 24. At the beginning of the data analysis, the background characteristics of the participants in the research were described by group. Categorical and ordinal variables were described with frequencies and percentages, and Chi square analyses were calculated by group. Continuous variables were described with means and standard deviations, and t-tests were calculated for group differences. Then, internal consistencies for the study variables (Cronbach a) were calculated, and total scores were computed from item means. The research variables were described with averages and deviations, and Pearson correlations were calculated for them. 
Prior to the examination of the study hypotheses, correlations were examined between the study's variables and background characteristics, in order to identify the need to control for background characteristics during hypothesis checking. Pearson correlations were calculated for continuous background characteristics, and Point-biserial correlations were calculated for dichotomous background characteristics.

The research hypotheses were examined with multivariate analyses of covariance (MANCOVA), comparing the three groups, while controlling for background characteristics that were found to be relevant: age, years of education, marital status, children from the relationship and occupational status.

Then, Pearson correlations were calculated among study variables for each group. The differences were examined with multivariate analyses of covariance (MANCOVA) according to: the existence of the relationship or its termination, the existence of a child diagnosed on the autism spectrum, the type of diagnosis of the partner and the timing of the diagnosis.

Prior to the gathering of the data, the power was calculated for the analysis of variance in order to examine the differences between the groups. This analysis showed that for medium size effect $a=.05,0.30$, two groups and 4 control variables, and power 0.80 , the required sample is 90 participants. Retroactively, for medium size effect $a=.05,0.30$, three groups and 5 control variables, and given a sample of 648 participants, the power obtained was 0.99 .

\section{Results}

Significant positive correlations were found among physical abuse, psychological abuse, PHQ15 somatic symptom subscale, PHQ somatic symptom module, PHQ depression module and Beck Depression Inventory. A positive correlation was found between perceived health and SWB. Significant negative correlations were found among all scales of abuse, somatic symptoms, depression, and perceived health and SWB (see Table 2).

All research hypotheses were fully and significantly confirmed $(p<.001)$. Significant differences were found for both physical and psychological abuse among women from the two experiential groups and the control group $(p<.001)$. Women with diagnosed partners and women who suspect their partners to be on the autism spectrum similarly reported being subjected to physical and psychological abuse at a significantly higher rate than women in a NT relationship (see Table 3). Furthermore, for all three groups, the report about psychological abuse was at a significantly higher rate than the report about physical abuse $(p<.001)$.

Findings also revealed a significant gap that differentiated between the two experiential groups and the control group $F(2,640)=59.71, p<.001, \eta^{2}=.157$, showing a higher rate of psychological abuse than of physical abuse for women whose partners have been diagnosed with ASD $\left(\eta^{2}=.463\right)$ and women who suspect their partners to be on the autism spectrum $\left(\eta^{2}=.476\right)$, in comparison with women in NTR $\left(\eta^{2}\right.$ $=.141)$. 
Significant differences were found among the groups for the three measures of health that were used in the study $(p<.001)$. Women with diagnosd partners and women who suspect their partners to be on the autism spectrum reported similar and significantly different levels of health than women in the control group. They reported lower perceived physical health, more somatic symptoms and higher somatic symptom severity (see Table 3 ).

Significant differences were found among the groups for the two measures of depression that were used in the study $(p<.001)$. Women with diagnosed partners and women who suspect their partners to be on the autism spectrm reported significantly higher levels of depression (see Table 3) and higher depressive symptom severity than women in NTR (see Table 4).

Significant differences were also found among the groups for the personal sense of well-being $(p<.001)$. Women with diagnosed partners and women who suspect their partners to be on the autism spectrum reported significantly similar and lower levels of SWB than women in NTR (see Table 3).

\section{Discussion}

One of the main findings that emerged from this research was the lack of difference between women whose partners were formally diagnosed with ASD and women who suspected their partners to be on the autism spectrum, for most of the examined measures. Thereby, it is important to acknowledge that the existence or not of a formal diagnosis is unimportant regarding the adult population which reached maturity before high-functioning autism was entered into the book of psychiatric diagnoses (American Psychiatric Association, 2013 ; Baron-Cohen et al., 2005 ; Center for Disease Control and Prevention [CDC], 2016 ; Lai \& Baron-Cohen, 2015; Lewis, 2017 ; Myhill \& Jekel, 2008).

Our results showed that women in NR reported being victims of physical and psychological abuse at a higher rate than women in NTR. Findings also revealed a significant gap, showing a higher rate of psychological abuse than physical abuse for women with diagnosed partners and women who suspected their partners to be on the autism spectrum, in comparison with women in NTR.

It is well known that physical abuse is always accompanied by psychological abuse, whereas psychological abuse can occur separately, and is more common (Shepard \& Campbell, 1992). Unfortunately, while physical abuse is getting wide-scale public exposure and serious consideration by the law, psychological abuse is not being treated with the same level of seriousness, unless it develops into physical abuse, or accompanies it, although psychological abuse was found to be related to worse physical and mental consequences than physical abuse (Coker et al, 2002 ; Lawrence, Yoon, Langer \& Ro, 2009).

A large number of research studies provide evidence for the biological impacts of recurrent traumatic experiences and constant exposure to stress (Luxenberg, Spinazzola \& Van der Kolk, 2001). It is important to note that depression and PTSD are the most common comorbid disorders among women who suffer from abuse in their intimate relationships (Campbell, 2002). Women who suffer from domestic abuse 
frequently seek help from the public health care system, complaining about a large variety of physical and mental symptoms which are likely caused by the chronic stress they experience within their relationships (Campbell, 2002).

An extensive review of professional medical literature reveals that one out of every 5 patients complains about symptoms which often remain without any medical explanation, such as: headaches, fatigue, back pain, dizziness or Irritable Bowel Syndrome. When long lasting, these complaints can lead to a series of redundant tests and treatments that overload the public health system (Van Ravsteijn, 2013). In the present study, we used the Health Questionnaire PHQ-15, as it includes a large variety of symptoms for which medical explanation is often missing and which is, according to the professional literature, also characteristic of recurrent trauma (Herman, 1992 ; Luxenberg, Spinazzola \& Van der Kolk, 2001).

The assumption underlying the dominant bio-medical model is that human suffering is caused by anatomical or physiological abnormality. Nonetheless, it is nowadays clear that genetic and biological factors cannot in themselves explain the development of affective disorders, in particular, depressive disorders, and there is an agreement that psychological environmental factors such as stress, play a major role in the development of these disorders (Van Ravesteijn, 2013). The world's leading social scientists claim that the main reasons for depression are not biological, but environmental and that the experience of pain is therefore not the expression of a pathology, but rather a clear signal showing that natural psychological needs are not being met (Hary, 2018).

A large number of research studies indicate that marital distress accelerates the appearance of depressive symptology and that marital disharmony predicts depression (Dehle \& Weiss 1998 ; Proulx, Helms \& Buehler, 2007). The presence of both depression and marital distress was found to be susceptible to gender differences and affect women more severely than men. It was also found that low levels of intimacy with a romantic partner was the most significant variable in the development of depression in women (Dehle \& Weiss, 1998).

There are very few studies which look into the ways in which ASD impacts romantic relationships. The existent sources of information indicate that women in NR experience extreme emotional deprivation and suffer from severe harm to their physical and mental well-being (Aston, 2001, 2003 ; Grigg, 2012 ; Lewis, 2017 ; Millar-Powell, 2015 ; Myhill \& Jekel, 2008 ; Rench, 2014). Still, none of these sources could supply valid and reliable proof as to how NR affect the NT partner in the context of intimate relationships (Bostock-Ling, Cumming and Bundy, 2012).

The findings of the current study strongly indicate that women in NR qualify their physical and mental health as worse than women who are in NTR. They report a significantly higher rate of somatic symptoms and higher somatic symptom severity. They also report significant higher levels of depression, higher depressive symptom severity and a lower sense of SWB than women in NTR. Findings of the current research support previous studies as well as the vast nonscholarly literature in this field. The findings point at a severe condition of distress shared by women in NR and require serious consideration on the part of medical and mental health professionals. 


\section{Limitations and Future Directions}

The main limitations of the study were reliance on self-report instruments, the use of convenience sampling and the impossibility of pointing towards causation.

It is possible that women who seek support were particularly interested in participating in a study about this topic. If such a selection bias exists, then women in NR who are content in their relationships might be underrepresented in our sample.

In addition, due to lack of previously conducted empirical studies on the subject, there were limited possibilities to compare between the findings of this study and previous studies. Future research should continue the direction of this study and address its limitations

Conventional couple counseling that does not address the specific difficulties brought on by autistic traits is not helpful for NR and may worsen women's condition and lead to the termination of the relationship (Grigg, 2012 ; Millar-Powell, 2015). Consequently, in our opinion, it would be best to address couples and women in NR and learn from them about their needs in terms of required help and support. It would also be interesting to learn from the positive experience of neurodiverse couples and women who are content with their NR. A comparative future study may point towards effective strategies for dealing with the cahallenges of NR.

\section{Implications and Applications}

As of right now, most professionals aren't trained or lack the experience to recognize or diagnose ASD in adults. Hence, they fail to provide efficient help for neurodiverse couples and women in such relationships. Given the fact that ASD diagnosis is on a constant rise and that most of the high-functioning adult population is still undiagnosed, it is to be expected that the number of women and couples who will need informative guidance and therapeutic intervention specializing in this field, will grow as well in the years to come. Therefore, it is of utmost importance to enrich the expertise of professionals, to raise the awareness regarding NR and to increase practitioners' alertness and potential for assissting neurodiverse couples and women in NR.

The current research has significant clinical and practical implications concerning the need to develop educational programs for professionals and effective clinical interventions, with the aim of providing appropriate support for this population of women and offer treatment that can relieve and ease their distress. It also points at an urgent need to develop preventative, instructional and therapeutic measures to help neurodiverse couples preserve and maintain their relationships.

In conclusion, the present study with its preliminary findings enriches the current literature, which is lacking. The present study's importance is magnified by the fact that to the best of our knowledge, it is the first empirical research focusing on the physical and mental well-being of women in NR. Obviously more research needs to be done. Results emerging from this pilot study should encourage further research in 
this field, that in turn, would contribute to raising public and clinical awareness and would eventually lead to change in the recognition and treatment of neurodiverse couples and of women in NR.

\section{Abbreviations}

HFA:high-functioning autism

ASD: autism spectrum disorder

NT: neurologically typical

NR: neurodiverse relationships

NTR: neurologically typical relationships

\section{Declarations}

\section{Ethics approval and consent to participate}

Approval to conduct the study was received from the Human Subject Review Committee of the Professional School of Psychology. All procedures performed were in accordance with the ethical standards of the institutional research committee and with the 1964 Helsinki declaration and its later amendments.

\section{Consent for publication}

Informed consent was provided by all participants. An internet site was constructed which provided detailed information about the study in English, with links to a research consent form and questionnaires. Participation in the study was anonymous, voluntary, and the identifying details of the participants were kept secret by means of strict technological security measures.

\section{Availability of data and materials}

The datasets generated and analysed during the current study are not publicly available but may be obtained from the corresponding author on reasonable request.

\section{Competing interests}

The authors declare that they have no competing interests.

\section{Funding}

The authors received no financial support for the research, authorship, and/or publication of this article.

\section{Authors' contributions}


PA developed the study concept and design, carried out the literature search, screening, extraction, and summary of literature, collected the data, performed the analysis and interpretation, and wrote the initial draft of the manuscript.

ZS supervised the research, contributed to the conceptualization and design of the study, assisted with data analysis and interpretation and with manuscript preparation.

TA reviewed and edited the manuscript.

All authors read and approved the final version of the manuscript.

\section{Corresponding author}

Correspondence to Pnina Arad.

\section{Acknowledgements}

We thank all the individuals who participated in this research.

\section{References}

1. American Psychiatric Association. Diagnostic and Statistical Manual of Mental Disorders DSM-4TM. Washington, D.C: American Psychiatric Publishing Association; 1994.

2. American Psychiatric Association. (2013). Diagnostic and Statistical Manual of Mental Disorders Fifth Edition DSM-5 TM. Washington, D.C: American Psychiatric Publishing. Retrieved from http://displus.sk/DSM/subory/dsm5.pdf.

3. Aston M. The other half of Asperger syndrome (1 ed.). London: National Autistic Society; 2001.

4. Aston M. Aspergers in Love: Couple Relationships and Family Affairs (Kindle Ed). London: Jessica Kingsley Publishers; 2003.

5. Attwood T. (2006). Asperger's Syndrome: A Guide for Parents and Professionals (1 ed). London and Philadelphia: Jessica Kingsley Publishers.

6. Baio J, Wiggins L, Christensen DL, et al. Prevalence of Autism Spectrum Disorder Among Children Aged 8 Years - Autism and Developmental Disabilities Monitoring Network, 11 Sites, United States, 2014. MMWR Surveillance Summaries. 2018;67(6):1-23.

DOl:http://dx.doi.org/10.15585/mmwr.ss6706a1.

7. Baron-Cohen S, Wheelwright S, Robinson J, Woodbury-Smith M. The adult Asperger assessment: A diagnostic method. J Autism Dev Disord. 2005;35(6):807-19.

8. Beck AT, Steer RA, Brown GK. Beck Depression Inventory Second Edition Manual. San Antonio: The Psychological Corporation; 1996.

9. Bolling KL. (2015). Asperger's Syndrome/Autism Spectrum Disorder and Marital Satisfaction: A Quantitative Study. (Doctoral dissertation, Antioch University). Available from ProQuest Dissertations and thesis database. 
10. Bostock-Ling JS, Cumming SR, Bundy A. Life Satisfaction of Neurotypical Women in Intimate Relationship with an Asperger's Syndrome Partner: A Systematic Review of the Literature. Journal of Relationships Research. 2012;3:95-105. Doi:jrr.2012.9/10.1017.

11. Bostock-Ling JS. (2017). Life Satisfaction of Neurotypical Women in Intimate Relationship with a Partner Who Has Asperger's Syndrome: An Exploratory Study. (Master Dissertation, University of Sydney).

12. Buhrmester M, Kwang T, Gosling SD. Amazon's Mechanical Turk: a new source of inexpensive, yet high-quality, data? Perspectives on Psychological Science. 2011;6(1):3-5.

13. Campbell JC. Health consequences of intimate partner violence. The Lancet. 2002;359:1331-6.

14. Centers for Disease Control and Prevention [CDC]. (2016). Autism Spectrum Disorder (ASD): Data \& Statistics. Retrieved from .

15. Coker AL, Davis KE, Arias I, Desai S, Sanderson M, Brandt HM, Smith PH. Physical and mental health effects of intimate partner violence for men and women. Am J Prev Med. 2002;23(4):260-8.

16. Dehle C, Weiss RL. Sex difference in prospective associations between marital quality and depressed mood. Journal of Marriage the Family. 1998;60:1002-11.

17. Grigg C. Aspia's Handbook for Partner Support; A Collection of Aspia's Best Information for the Support of Partners of Adults with Asperger's Syndrome. Australia: Carol Grigg; 2012.

18. Hary J. Lost Connections. Uncovering the Real Causes of Depression and the Unexpected Solutions. U.S.A: Bloomsbury; 2018.

19. Herman JL. Complex PTSD: A syndrome in survivors of prolonged and repeated trauma. J Trauma Stress. 1992;5:377-91.

20. Hobfoll SE, Vinokur AD, Pierce PF, Lewandowski-Romps L. (2012). Perceived Health Questionnaire [Database record]. Retrieved from PsycTESTS. doi: 10.1037/t34645-000.

21. Hobfoll SE, Vinokur AD, Pierce PF, Lewandowski-Romps L. The combined stress of family life, work, and war in Air Force men and women: A test of conservation of resources theory. International Journal of Stress Management. 2012;19(3):217-37. doi:10.1037/a0029247.

22. Jasper F, Hiller W, Rist F, Bailer J, Witthöft M. Somatic symptom reporting has a dimensional latent structure: Results from taxometric analyses. J Abnorm Psychol. 2012;121(3):725-38. doi:10.1037/a0028407.

23. Kroenke K, Spitzer RL, DeGruy FV, Swindle R. (1998). 15-item Patient Health Questionnaire [Database record]. Retrieved from PsycTESTS. doi: 10.1037/t19590-000.

24. Kroenke K, Spitzer RL, DeGruy FV, Swindle R. A symptom checklist to screen for somatoform disorders in primary care. Psychosomatics. 1998;39:263-72. doi:10.1016/S0033-3182(98)71343-.

25. Lai MC, Baron-Cohen S. Identifying the Lost Generation of Adults with Autism Spectrum Conditions. Lancet Psychiatry. 2015;2:1013-27.

26. Lau W, Peterson CC. Adults and children with Asperger syndrome: Exploring adult attachment style, marital satisfaction and satisfaction with parenthood. Research in Autism Spectrum Disorders. 2011;5(1):392-9. doi:10.1016/j.rasd.2010.06.001. 
27. Lawrence E, Yoon J, Langer A, Ro E. Is psychological aggression as detrimental as physical aggression? The independent effects of psychological aggression on depression and anxiety symptoms. Violence victims. 2009;24(1):20-35.

28. Lehnhardt FG, Gawronski A, Pfeiffer K, Kockler H, Schilbach L, Vogeley K. The investigation and differential diagnosis of Asperger syndrome in adults. Dtsch Arztebl Int. 2013;110(45):755-63. doi:10.3238/arztebl.2013.0755.

29. Lewis LF. We will never be normal: the experience of discovering a partner has autism spectrum disorder. Journal of Marital Family Therapy. 2017. doi:10.1111/jmft.12231.

30. Luxenberg T, Spinazzola J, Van der Kolk B. Complex Trauma and Disorders of Extreme Stress (DENOS). Diagnosis, Part One: Assessment. Directions in Psychiatry, (21), 2001.

31. Millar-Powell N. (2015). Caregiver burden and relationship satisfaction in ASD-NT intimate relationships. Empirical thesis submitted in partial fulfilment of the requirements for the degree of Master of Research-Psychology. Australia, Sydney, Macquarie University. Retrieved from: http://hdl.handle.net/1959.14/1073917.

32. Moum T, Naess S, Sorensen T, Tambs K. Hypertension Labeling, Life Events and Psychological WellBeing. Psychol Med. 1990;20(3):635-46.

33. Myhill G, Jekel D. (2008). Asperger marriage: Viewing partnerships thru a different lens. FOCUS Homestudy Course. National Association of Social Workers. Retrieved fromhttp://www.naswma.org/association/8381/files/FCE_AspergerMarriage.pdf.

34. Pavot W, Diener E. Review of the satisfaction with life scale. Psychol Assess. 1993;5(2):164.

35. Pollmann MMH, Finkenauer $\mathrm{C}$, Begeer $\mathrm{S}$. Mediators of the link between autistic traits and relationship satisfaction in a non-clinical sample. J Autism Dev Disord. 2010;40(4):470-8. doi:10.1007/s10803009-0888-z.

36. Proulx CM, Helms HM, Buehler C. Marital Quality and Personal Well Being: a meta-analysis. Journal of Marriage Family. 2007;69(3):576-93.

37. Rench C. (2014). When Eros meets Autos: Marriage to someone with autism spectrum disorder. (Doctoral dissertation, Capella University). Available from Proquest Dissertations and thesis database.

38. Renty J, Roeyers H. Individual and marital adaptation in men with autism spectrum disorder and their spouses: The role of social support and coping strategies. J Autism Dev Disord. 2007;37(7):1247-55. doi:10.1007/s10803-006-0268-x.

39. Røysamb E, Harris JR, Magnus P, Vitters $\varnothing$ J, Tambs K. Subjective well- being: Sex-specific effects of genetic and environmental factors. Personality Individ Differ. 2002;32(2):211-23. doi:10.1016/S01918869(01)00019-8, ( 2002 by Elsevier. Reproduced by Permission of Elsevier.

40. Røysamb E, Harris JR, Magnus P, Vitters $\varnothing$ J, Tambs K. (2002). Subjective Well-Being--Short Scale [Database record]. Retrieved from PsycTESTS. doi: 10.1037/t13453-000.

41. Shepard MF, Campbell JA. (1992). Abusive Behavior Inventory [Database record]. Retrieved from PsycTESTS. doi: 10.1037/t01967-000. 
42. Shepard MF, Campbell JA. The Abusive Behavior Inventory: A measure of psychological and physical abuse. Journal of Interpersonal Violence. 1992;7(3):291-305. doi: 10.1177/088626092007003001, (c) 1992 by SAGE Publications. Reproduced by Permission of SAGE Publications.

43. Van Ravesteijn H. Minding the Body. Netherlands: Nijmegen; 2013.

44. Van Ravesteijn $H$, Wittkampf $K$, Lucassen P, van der Lisdonk E, van de Hoogen $H$, van Weert $H, .$. . Speckens A. Detecting somatoform disorders in primary care with the PHQ-15. Annals of Family Medicine. 2009;7:232-8. doi:10.1370/afm.985.

45. Vaughn MMS. (2010). Symptoms of Asperger's disorder predict dyadic relationship expectations for same-sex friends, cross-sex friends, and romantic partners. (Doctoral dissertation, University of Texas at San Antonio).

\section{Tables}

Table 1: Distribution of Background Characteristics Across the Three Groups of Participants

$(N=648)$ 
Total Formal Diagnosis Suspicion NT Partner Difference

\begin{tabular}{|c|c|c|c|c|c|c|}
\hline & & $(n=648)$ & $(n=228)$ & $(n=203)$ & $(n=217)$ & \\
\hline & & $N$ & $N$ & $N$ & $N$ & \\
\hline & & $(\%)$ & $(\%)$ & (\%) & (\%) & \\
\hline \multirow[t]{12}{*}{ Country } & \multirow{2}{*}{$\begin{array}{l}\text { United } \\
\text { States }\end{array}$} & 475 & 139 & 131 & 205 & \multirow{6}{*}{$\begin{array}{l}\chi^{2}(10)= \\
89.69 * \star \star\end{array}$} \\
\hline & & (73.3) & $(61.0)$ & $(64.5)$ & $(94.5)$ & \\
\hline & \multirow[t]{2}{*}{ Britain } & 56 & 27 & 27 & 2 & \\
\hline & & (8.6) & $(11.8)$ & (13.3) & $(0.9)$ & \\
\hline & \multirow{2}{*}{$\begin{array}{l}\text { Australia \& } \\
\text { New } \\
\text { Zealand }\end{array}$} & 43 & 26 & 17 & 0 & \\
\hline & & (6.6) & (11.4) & (8.4) & (0) & \\
\hline & \multirow[t]{2}{*}{ Canada } & 17 & 13 & 2 & 2 & \\
\hline & & $(2.6)$ & (5.7) & $(1.0)$ & $(0.9)$ & \\
\hline & \multirow[t]{2}{*}{ Europe } & 48 & 20 & 22 & 6 & \\
\hline & & (7.4) & (8.8) & (10.8) & (2.8) & \\
\hline & \multirow[t]{2}{*}{ Other } & 9 & 3 & 4 & 2 & \\
\hline & & (1.4) & (1.3) & $(2.0)$ & $(0.9)$ & \\
\hline \multirow{2}{*}{$\begin{array}{l}\text { Marital } \\
\text { Status }\end{array}$} & \multirow{2}{*}{$\begin{array}{l}\text { In a } \\
\text { relationship }\end{array}$} & 557 & 200 & 168 & 189 & \multirow{2}{*}{$\begin{array}{l}\chi^{2}(2)= \\
2.54\end{array}$} \\
\hline & & $(86.0)$ & $(87.7)$ & $(82.8)$ & (87.1) & \\
\hline \multirow{2}{*}{$\begin{array}{l}\text { Living } \\
\text { Arrangements }\end{array}$} & \multirow{2}{*}{$\begin{array}{l}\text { Living } \\
\text { together }\end{array}$} & 533 & 197 & 156 & 180 & \multirow{2}{*}{$\begin{array}{l}\chi^{2}(2)= \\
6.83^{\star}\end{array}$} \\
\hline & & $(82.3)$ & $(86.4)$ & (76.8) & (82.9) & \\
\hline \multirow{2}{*}{$\begin{array}{l}\text { Children from } \\
\text { the } \\
\text { Relationship }\end{array}$} & \multirow[t]{2}{*}{ Yes } & 387 & 141 & 116 & 130 & \multirow{2}{*}{$\begin{array}{l}\chi^{2}(2)= \\
0.99\end{array}$} \\
\hline & & (59.7) & $(61.8)$ & $(57.1)$ & (59.9) & \\
\hline \multirow{5}{*}{$\begin{array}{l}\text { Occupational } \\
\text { Status }\end{array}$} & \multirow[t]{4}{*}{ Employed } & 451 & 153 & 130 & 168 & \multirow{2}{*}{$\begin{array}{l}\chi^{2}(2)= \\
9.91^{\star \star}\end{array}$} \\
\hline & & (69.6) & $(67.1)$ & $(64.0)$ & (77.4) & \\
\hline & & $M$ & $M$ & $M$ & $M$ & $F(d f)$ \\
\hline & & $(S D)$ & $(S t D)$ & $(S D)$ & $(S D)$ & $\left(n^{2}\right)$ \\
\hline & & & Pag & & & \\
\hline
\end{tabular}




\begin{tabular}{|c|c|c|c|c|c|c|}
\hline Age & $19-69$ & $\begin{array}{l}42.16 \\
(10.76)\end{array}$ & $\begin{array}{l}42.62 \\
(11.04)\end{array}$ & $\begin{array}{l}44.44 \\
(10.87)\end{array}$ & $\begin{array}{l}39.54 \\
(9.81)\end{array}$ & $\begin{array}{l}\mathrm{F}(2,645) \\
= \\
11.57^{\star \star \star \star} \\
(.035)\end{array}$ \\
\hline $\begin{array}{l}\text { Years of } \\
\text { Education }\end{array}$ & $0-30$ & $\begin{array}{l}15.20 \\
(4.35)\end{array}$ & $\begin{array}{l}14.95 \\
(4.86)\end{array}$ & $\begin{array}{l}15.46 \\
(4.53)\end{array}$ & $\begin{array}{l}15.23 \\
(3.54)\end{array}$ & $\begin{array}{l}F(2,645) \\
=0.76 \\
(.002)\end{array}$ \\
\hline $\begin{array}{l}\text { Length of the } \\
\text { Relationship } \\
\text { (years) }\end{array}$ & $1-55$ & $\begin{array}{l}13.37 \\
(10.21)\end{array}$ & $\begin{array}{l}14.11 \\
(10.44)\end{array}$ & $\begin{array}{l}13.95 \\
(10.21)\end{array}$ & $\begin{array}{l}12.06 \\
(9.86)\end{array}$ & $\begin{array}{l}F(2,645) \\
=2.74 \\
(.008)\end{array}$ \\
\hline $\begin{array}{l}\text { Time from } \\
\text { the End of the } \\
\text { Relationship } \\
(n=76)\end{array}$ & $0.1-16$ & $\begin{array}{l}3.42 \\
(3.46)\end{array}$ & $\begin{array}{l}3.02 \\
(3.54)\end{array}$ & $\begin{array}{l}3.13 \\
(2.81)\end{array}$ & $\begin{array}{l}4.20 \\
(4.05)\end{array}$ & $\begin{array}{l}\mathrm{F}(2,73)= \\
0.84 \\
(.023)\end{array}$ \\
\hline
\end{tabular}

${ }^{\star} p<.05,{ }^{*} p<.01, * \star \star p<.001$

Table 2: Averages, Standard Deviations and Correlations among Study Variables $(N=648)$

\begin{tabular}{|c|c|c|c|c|c|c|c|c|}
\hline & $(S D) M$ & .2 & .3 & 4. & .5 & 6. & 7. & 8. \\
\hline $\begin{array}{l}\text { 1.Physical Abuse } \\
(1-5)\end{array}$ & $\begin{array}{l}1.29 \\
(0.47)\end{array}$ & $.68^{\star \star \star}$ & $-.19 \star \star \star$ & $.29 * \star \star$ & 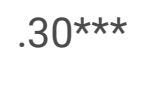 & $.18^{\star \star \star}$ & $.29 * \star \star$ & 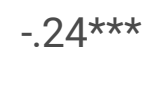 \\
\hline $\begin{array}{l}\text { 2. Psychological } \\
\text { Abuse (1-5) }\end{array}$ & $\begin{array}{l}2.05 \\
(0.86)\end{array}$ & & 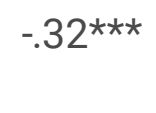 & $.45^{\star \star \star}$ & $.44^{\star \star \star}$ & $.34^{\star \star \star}$ & $.46^{\star \star \star}$ & $-.37 \star \star \star$ \\
\hline $\begin{array}{l}\text { 3.Perceived Health } \\
(1-5)\end{array}$ & $\begin{array}{l}3.52 \\
(1.02)\end{array}$ & & & $-.63^{\star \star \star}$ & $-.62^{\star \star \star}$ & $-.49 \star \star \star$ & $-.56^{\star \star \star}$ & $.57^{\star \star \star \star}$ \\
\hline $\begin{array}{l}\text { 4. PHQ } 15 \text { Subscale } \\
(0-30)\end{array}$ & $\begin{array}{l}9.79 \\
(5.86)\end{array}$ & & & & $.98^{\star \star \star}$ & $.74^{\star \star \star}$ & $.67^{\star \star \star}$ & 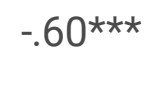 \\
\hline $\begin{array}{l}\text { 5. Somatic Symptom } \\
\text { Module }(0-26))\end{array}$ & $\begin{array}{l}7.45 \\
(4.96)\end{array}$ & & & & & $.60 \star \star \star$ & $.63^{\star \star \star}$ & $-.55^{\star \star \star}$ \\
\hline $\begin{array}{l}\text { 6. Depression } \\
\text { Module }(0-4)\end{array}$ & $\begin{array}{l}2.34 \\
(1.32)\end{array}$ & & & & & & $.61^{\star \star \star}$ & $-.58^{\star \star \star}$ \\
\hline $\begin{array}{l}\text { 7. Beck Depression } \\
(0-63)\end{array}$ & $\begin{array}{l}16.11 \\
(11.65)\end{array}$ & & & & & & & 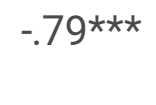 \\
\hline $\begin{array}{l}\text { 8. Subjective Well- } \\
\text { being }(0-10)\end{array}$ & $\begin{array}{l}4.60 \\
(2.37)\end{array}$ & & & & & & & \\
\hline$* * p<.001$ & & & & & & & & \\
\hline
\end{tabular}




\begin{tabular}{|c|c|c|c|c|}
\hline Difference & $\begin{array}{l}\text { NT } \\
\text { Partner }\end{array}$ & Suspicion & $\begin{array}{l}\text { Formal } \\
\text { Diagnosis }\end{array}$ & \\
\hline & $(n=217)$ & $(n=203)$ & $(n=228)$ & \\
\hline$F(2,640)\left(\eta^{2}\right)$ & $M(S D)$ & $M(S D)$ & $M(S D)$ & \\
\hline $\begin{array}{l}11.56 \star \star \star \\
(.035)\end{array}$ & $1.17(0.46)$ & $1.38(0.50)$ & $1.33(0.42)$ & Physical Abuse (1-5) \\
\hline $\begin{array}{l}62.02 \star \star \star \\
(.162)\end{array}$ & $1.57(0.72)$ & $2.37(0.86)$ & $2.23(0.79)$ & Psychological Abuse (1-5) \\
\hline $\begin{array}{l}17.96^{\star \star \star} \\
(.053)\end{array}$ & $3.88(0.90)$ & $3.41(0.97)$ & $3.28(1.08)$ & Perceived Health (1-5) \\
\hline $\begin{array}{l}56.90^{\star \star \star} \\
(.151)\end{array}$ & $6.59(4.41)$ & $10.78(5.72)$ & $11.94(5.90)$ & PHQ 15 Subscale (0-30) \\
\hline $\begin{array}{l}49.18^{\star \star \star} \\
(.133)\end{array}$ & $4.92(3.54)$ & $8.25(4.95)$ & $9.14(5.19)$ & $\begin{array}{l}\text { Somatic Symptom Module (0- } \\
\text { 26) }\end{array}$ \\
\hline $\begin{array}{l}44.44 \star \star \star \\
(.122)\end{array}$ & $1.67(1.28)$ & $2.53(1.24)$ & $2.80(1.16)$ & Depression Module (0-4) \\
\hline $\begin{array}{l}71.04 * \star \star \\
(.182)\end{array}$ & $9.00(8.90)$ & $18.96(10.72)$ & $20.35(11.63)$ & Beck Depression (0-63) \\
\hline $\begin{array}{l}58.99 * \star \star \\
(.156)\end{array}$ & $5.95(2.34)$ & $4.03(2.00)$ & $3.82(2.16)$ & Subjective Wellbeing (0-10) \\
\hline
\end{tabular}

${ }^{\star} p<.05,{ }^{* \star} p<.001,{ }^{\star \star \star} p<.001$

Table 4: Distribution of Severity of Depressive Symptoms by Group $(N=648)$ 


\begin{tabular}{llll}
$\begin{array}{l}\text { NT Partner } \\
)=217 n(\end{array}$ & $\begin{array}{l}\text { Suspicion } \\
\text { N } 203 n(\end{array}$ & $\begin{array}{l}\text { Formal Diagnosis } \\
(n=228)\end{array}$ & \\
\hline$N$ & $N$ & $N$ & Depression Severity \\
$(\%)$ & $(\%)$ & $(\%)$ & Minimal \\
\hline 165 & 68 & 66 & $(0-13)$ \\
$(76.0)$ & $(33.5)$ & $(28.9)$ & Low \\
\hline 23 & 39 & 38 & $(14-19)$ \\
$(10.6)$ & $(19.2)$ & $(16.7)$ & Medium \\
19 & 65 & 71 & $(20-28)$ \\
$(8.8)$ & $(32.0)$ & $(31.1)$ & Severe \\
\hline 10 & 31 & 53 & $(29-63)$ \\
$(4.6)$ & $(15.3)$ & $(23.2)$ &
\end{tabular}

$\chi 2(6)=127.20, p<.001$ 